\title{
Irovers: Real Time Unmanned Four Wheeled Iot Vehicles for Fire Monitoring and Extinguishing Using Sonic Waves
}

\author{
SUBASHINI.V, .ARTHI M, ANBARASI M, RAJAVENI R
}

\begin{abstract}
The aim of the proposed system is to build an autonomous mobile robot system for measuring the various levels of air and noise pollution as well as the fire monitoring and in case of fire, this robot is used to extinguish the fire using SONIC WAVES. This is a IOT based robot which moves autonomously avoiding obstacles using the IR sensor. This robot is used for temperature monitoring for the analysis of the presence of fire. The data from the robot is sent and received using WIFI in IOT. This mobile robot is capable of avoiding obstacles using IR sensor thereby it can be easily introduced in places of fire accidents for the process of fire extinguishing. The fire detection are monitored by using the temperature sensor. These information from the sensor are sent to the PIC microcontroller and then using the wi-fi the information are sent to the cloud. The fire extinguishing process is carried out by the sonic fire extinguisher.
\end{abstract}

Keywords: IOT, sensors

\section{INTRODUCTION}

Fires are the accidents which occur most frequently, whose causes are the most diverse and which require intervention methods and techniques adapted to the conditions and needs of each incident. Depending on the type of fire (nature of the material ablaze), meteorological conditions (wind) and the effectiveness of the intervention, material damage can be limited (a single car, building or production or storage warehouse installation), or affect wide areas (forest or agricultural fires, hydrocarbons, gas or other highly flammable products, storage or piping installations, harbor installations and rail or marine transport equipment). Explosions are in a different category.

Each type of fire is the object of specific technical prescriptions as regards prevention, intervention and the behavior of the population affected. It is also relevant to note that many fires have a criminal origin and that in times of armed conflict or crisis as well as of indirect wars (sabotage) human intervention also provokes major accidents attires, cotton (bales, loose, explosive dust), fodder (fermentation), fires in high warehouses, silos or underground garages as well as forest fires.

All these types of intervention are subject to special measures. For practical reasons it is best to refer to technical

Revised Manuscript Received on July 22, 2019.

Ms.V.Subashini, Assistant Professor,Sri Sairam Institute of technology,Chennai-44

Ms.Arthi M ,UG scholar, Sri Sairam Institute of technology,Chennai-44 Ms.Anbarasi M UG scholar, Sri Sairam Institute of technology,Chennai-44

Ms.Rajaveni R UG scholar, Sri Sairam Institute of technology,Chennai-44 documentation, which should be known or available to all security and fire-fighting services, and to national and regional disaster alarm and information centers.

This is especially the case for rescue and fire extinction on motorways, buildings designed to be Used by a great number of people (hospitals, hotels, cinemas, high-rise buildings, department stores, etc); fires affecting chimneys.

\section{III-LITERATURE SURVEY}

The first intelligent extinguisher used for eliminating a fire in domestic places. Also it is having a collision sensor to eliminating a obstacles. But the capacity of first intelligent extinguisher is less that is 1.5 liters. Termite is used for extreme hazard areas like aircraft fires and nuclear reactor and size also small. But cost is high. Approximately 95 lakhs.

\begin{tabular}{|c|c|c|c|c|}
\hline $\begin{array}{l}\text { S.n } \\
0\end{array}$ & Author & Paper Title & Year & Findings \\
\hline 1 & $\begin{array}{l}\text { B } \\
\text { Siregar,H } \\
\text { A }\end{array}$ & $\begin{array}{l}\text { Fire } \\
\text { Extinguisher }\end{array}$ & 2017 & $\begin{array}{l}\text { Smart phones are } \\
\text { the fire } \\
\text { extingusihing } \\
\text { robot.image is } \\
\text { captured by } \\
\text { camera in phones. }\end{array}$ \\
\hline 2 & $\begin{array}{l}\text { Varun S } \\
\text { V,Vinod } \\
\text { Rao.S }\end{array}$ & $\begin{array}{l}\text { Autonomous } \\
\text { fire } \\
\text { extinguisher } \\
\text { robot }\end{array}$ & 2017 & $\begin{array}{l}\text { robot } \\
\text { development } \\
\text { isguided by } \\
\text { sensors }\end{array}$ \\
\hline 3. & $\begin{array}{l}\text { Srinivas } \\
\text { Devarako } \\
\text { nda,Parve } \\
\text { en } \\
\text { Suvesu,H } \\
\text { ongzhang } \\
\text { Liu,Ruilin } \\
\text { Liu,Liviu } \\
\text { Iftode,Bad } \\
\text { ri Nath }\end{array}$ & $\begin{array}{l}\text { Real Time } \\
\text { air quality } \\
\text { monitoring } \\
\text { through } \\
\text { mobile } \\
\text { sensing in } \\
\text { metropolitan } \\
\text { areas. }\end{array}$ & 2013 & $\begin{array}{l}\text { Monitoring air } \\
\text { quality using fine } \\
\text { grained real time } \\
\text { pollution } \\
\text { measuremen } \\
\text { t. }\end{array}$ \\
\hline 4. & Poonam & $\begin{array}{l}\text { Intelligent } \\
\text { Fire }\end{array}$ & 2014 & $\begin{array}{l}\text { Multi Sensor } \\
\text { Rased security }\end{array}$ \\
\hline
\end{tabular}


Thats why it is not suitable for household. RF communication is control a voice operated intelligent fire extinguisher vehicle. User can send the input to robot through voice. But power requirement is very high.

\section{IV-BLOCK DIAGRAM:}
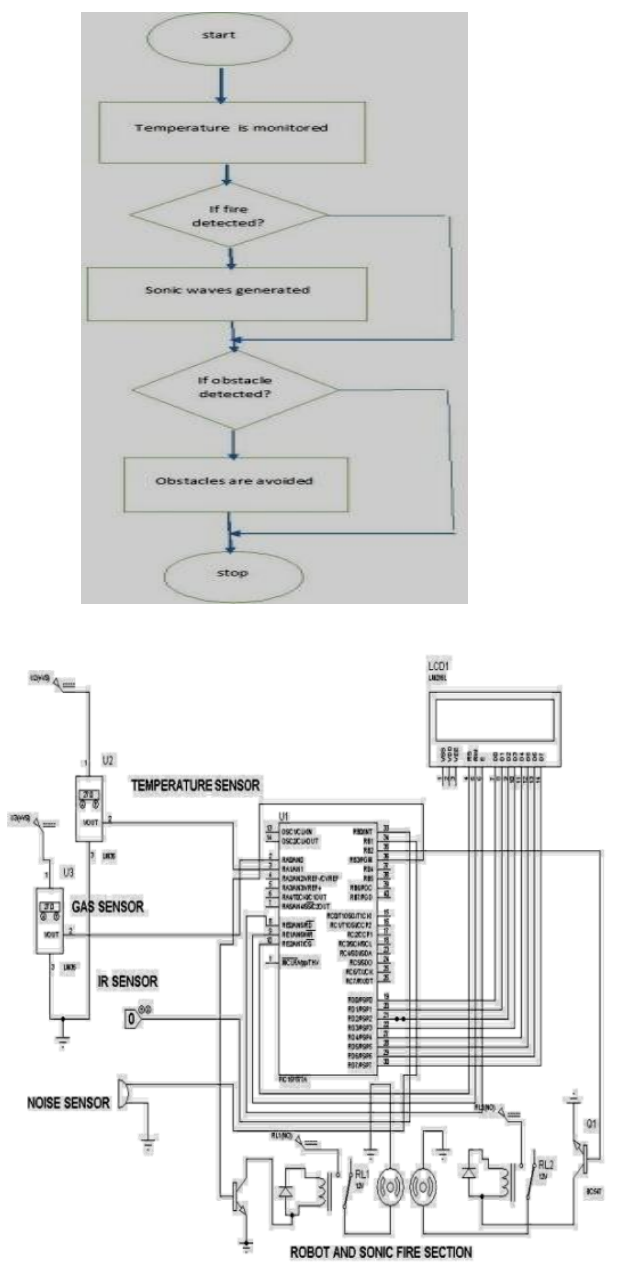

Generalized block diagram

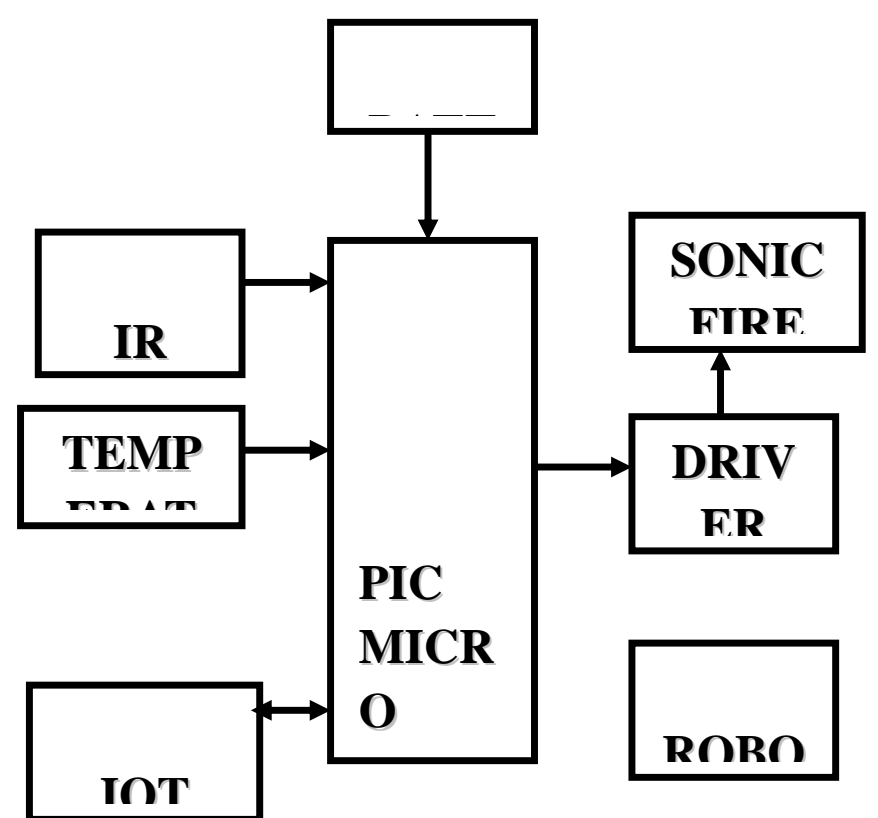

The existing system consists of water, $\mathrm{CO} 2$, ABC powder, wet chemical based automated fire extinguishing systems. This might cause water shortage and some sort of fire extinguishing is not completely possible in critical situations. Storage capacity is also limited and some of the existing system leaves a residue which is hazardous to human being and it is non eco friendly causing harmful effects on the environment.

\section{VI-PROPOSED WORK}

The proposed system consists of a mobile robot which moves in a defined path based on the information obtained from the sensor. The robot will be mounted with temperature sensor for monitoring the area. If any abnormal in that area found in robot that time to flow the sonic wave to extinguish the fire. Here robot will operate in IOT using to send and receive the data's from the information from the wifi.

Flowchart:

\section{APPLICATIONS \\ - Hospitals \\ - Industries}

Educational Institutions

\section{ADVANTAGES}

- Low cost,

- Automated operations

- Low power consumption

HARDWARE COMPONENTS

- Power supply unit.

-PIC microcontroller.

-Mike

-IR sensor.

- Temperature sensor

-Sonic fire.

1) SOFTWARE COMPONENTS

2) IOT, MPLAB

\section{OUTPUT:}



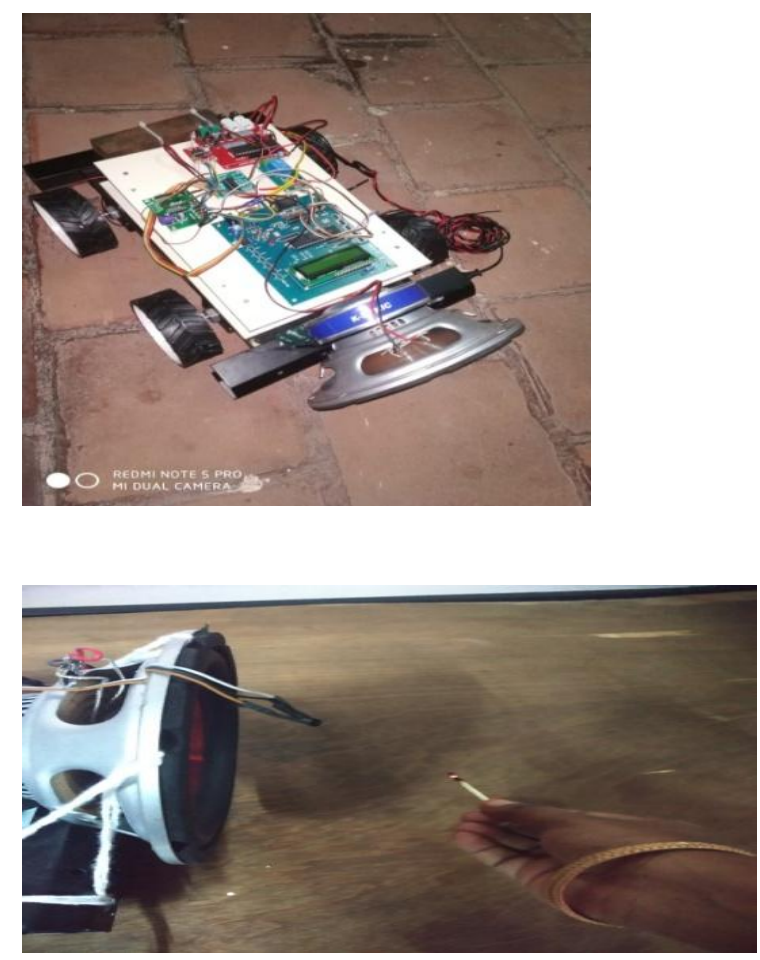

Fig.2 Extinguishing of fire

\section{CONCLUSION:}

Thus in this system we have detected the fire using temperature and the fire is automatically extinguished using sonic fire extinguisher mounted in the robot. The robot will automatically move and extinguish the fire. Using this system we are extinguishing fire without compromising any external resource. So the system will be efficient in all the places.

\section{FUTURE SCOPE}

The use of sonic waves is non toxic to humans such that it does not leave any residue. The greenhouse effect will be reduced and so the depletion of ozone will be also be reduced. The life time of engine as well as for human is also increased and thus this system is beneficial in all such case. The implementation of this mobile robot in large industries, malls, hospitals and in various sectors is easy and inexpensive. As the sonic fire extinguisher contains no coolant, it may be unable to prevent larger fires from reigniting after the sound is turned off. Thus using a coolant will make this extinguisher very much efficient.

\section{ACKNOWLEDGEMENT}

This paper is partially supports by Chuo University Personal Research Grant.

\section{REFERENCE}

- Yano, T., Takahashi, K., Kuwahara, T., and M. Tanabe (2010). Influence of Acoustic Perturbations and Acoustically Induced Thermal Convection on

- $\quad$ Premixed Flame Propagation. Microgravity Science and Technology (22), pp.155-161.

- $\quad$ Mikedi, K., Stavrakakis, P., Agapiou, A., ... (2013). Chemical, acoustic and optical response profiling for analyzing burning patterns. Sensors and Actuators (176), pp.290-298

- $\quad$ The Physics Classroom (n.d.). Sound is a Mechanical Wave.

http://www.physicsclassroom.com/Class/sound/U 11L1a.html [8] Vortex ring - Wikipedia: https://en.wikipedia.org/wiki/Vortex ring

- Frank, Obstacle Avoidance Robot Car, robotshop.com/letsmakerobots/obstacle-avoidance -robot-car-arduino, 2014, visited on October 29,2017. 